\title{
Barriers to the adequate management of cancer pain among Irish GPs
}

\author{
Geraldine McDarby*, David S Evans and Regina Kiernan \\ Department of Public Health, HSE West, Merlin Park Hospital, Galway, Ireland
}

\begin{abstract}
Context: The undertreatment of cancer pain remains problematic. This is despite the association of significant human and economic costs. The problem is multifaceted including patient, physician and system barriers. In Ireland, the majority of palliative care, including cancer pain management is delivered by General Practitioners (GPs).

Objectives: This study aimed to examine physician barriers through an examination of the knowledge, attitudes and behaviours surrounding the treatment of cancer pain among Irish GPs.

Methods: All GPs registered with the GP regulatory body in one region of Ireland $(\mathrm{n}=138)$ were asked to complete a confidential validated questionnaire to assess specific knowledge, attitudes, behaviours, recognised as barriers to adequate management of cancer pain. Data was analysed on SPSS (v21).

Results: A response rate of $76 \%$ was achieved. The results demonstrated high levels of knowledge and the attitudes and behaviours considered conducive to appropriate cancer pain management. However, small but significant deficits were found with the potential to contribute to ineffective prescribing. These included specific knowledge of opioid analgesics in relation to equivalence and dosage as well as exaggerated fears of psychological addiction and dependence. Further deficits identified have the potential to contribute to the underestimation of patient pain including a lack of recognition of the problem of undertreatment and the lack of use of formal pain assessment tools.
\end{abstract}

Conclusion: Even small deficits in knowledge and deviations from best practice in the area of cancer pain can contribute to the widespread problem of undertreatment in this population. The use of specialist training and formal assessment tools to support best practice among GPs was highlighted.

\section{Introduction}

Despite sustained international attention, evidence suggests that a significant proportion of cancer pain remains inadequately treated [1]. Poorly managed pain has significant implications for the individual in terms of functional impairment, psychological distress and the intensification of other symptoms, as well as leading to longer in-patient stays, higher resource utilisation and costs [2-4]. Barriers to appropriate treatment have been identified and classified as either system, patient or physician barriers. Physician barriers include incorrect knowledge of and misconceptions relating to analgesics, primarily opioids, which are the mainstay of cancer pain management [5].

Appropriate use of opioids is outlined by the WHO analgesic ladder, a validated approach to cancer pain that has been available since the 1980s. This approach advocates the use of regular, oral, slow release analgesics based on patient reported pain, with immediate release preparations being prescribed alongside slow release preparations [6]. Despite the availability of this guideline, physicians continue to have misconceptions about opioid use including the fear of addiction (confusing addiction with physiological dependence), and fearing opioids hasten death [7]. Evidence by contrast has been shown to refute these misconception $[8,9]$.

In Ireland, Primary Care Physicians (General Practitioners (GPs)) are responsible for the majority of cancer pain management. However, information is limited in terms of their knowledge, attitudes, and behaviours regarding the management of cancer pain. This study examined physician barriers to adequate analgesia among GPs in the West of Ireland.

\section{Methods}

\section{Design}

A quantitative descriptive cross-sectional design was utilised to allow comparison with international data. All GPs in the region currently registered with the Irish College of General Practitioners were contacted for inclusion, representing $98 \%$ of all GPs working in the region $(n=138)$. A cover letter stating the purpose and origin of the study was included as well as a self addressed, stamped envelope to facilitate return. Anonymity was assured in the cover letter and via a numbered coding system. Three postal reminders and one reminder telephone call to non-responders were undertaken at 4-6 weekly intervals.

\section{Instrument}

GP knowledge, attitudes and behaviours were assessed using a

Correspondence to: Geraldine McDarby, MFPHMI, Department of Public Health, HSE West, Merlin Park Hospital, Galway, Ireland, E-mail Geraldine.McDarby@hse.ie

Key words: cancer pain, physician barriers, knowledge, attitudes, behaviour, palliative

Received: June 02, 2017; Accepted: June 19, 2017; Published: June 22, 2017 
five-section questionnaire previously validated in a similar physician population [10]. Knowledge was assessed across six categories: Morphine Facts, Factual Basis for Assessment, Patient Role in Assessment, Opioid Dosing, Opioid Equivalency and Opioid Side Effects. Responses included 'agree,' 'disagree' and 'don't know.' Knowledge was considered adequate if the correct response was chosen by $70 \%$ or more of respondents. Two knowledge questions were removed to reflect differences in country practice and replaced by a single question examining the equivalence of MST and OxyContin, the two most commonly used opioid preparations in primary care in Ireland [11]. Attitudes were assessed across four categories: Salience of Pain Management, Lack of Fear of Addiction, Lack of Fear of Drug Regulation and Willingness to Prescribe Unrelated to Prognosis. Responses were recorded on a four point Likert scale ranging from 'strongly agree' to 'strongly disagree.' Behaviour was measured across seven categories: Obstacles to Proper Care Experienced, Frequency of Pain Assessment, Use of Formal Pain Assessment Tool, Fine Points of Prescribing and the prescribing frequencies of Paracetamol, Weak Opioids and Strong Opioids. Responses ranged from 'never' to 'always.' The final section included a list of potential barriers commonly presented in other studies with respondents asked to rate each barrier in terms of its importance within their practice setting from 0-10 with importance increasing with increasing number.

\section{Procedure}

\section{Statistical analysis}

Anonymised data was entered into SPSS (IBM V21). Knowledge, attitudes and behaviours are presented in the form of percentage correct as well as an overall category score. Scores were calculated using the schema developed by the designers of the original questionnaire [10]. For knowledge, correct responses were given a score of one, don't know was given a score of 0.5 while incorrect responses were given a score of zero. Responses to all questions were then summed to give a total score which was then expressed as a percentage for ease of interpretation. For appropriate attitude statements, Likeart scales were scored 1-4, with four given to the strongest level of agreement. For inappropriate attitude statements, scoring was reversed, with four given to the strongest level of disagreement. Scores for attitude statements were then summed to give a total score and are expressed out of a possible 100. In terms of appropriate behaviors, responses were scored in terms of frequency ranging from $0-3$, with three given to behaviours that were 'always' undertaken. As with attitudes, for behaviours that were considered inappropriate, scoring was reversed and scores were then summed to give a total score which is expressed as a percentage.

Scores in the knowledge, attitudes and behaviour categories were compared to demographic and practice characteristics using one-way ANOVA in the case of multiple categories and independent t-tests in the case of dichotomous variables. If small numbers prevented the use of ANOVA with multiple categories, categories were collapsed and independent $\mathrm{t}$ tests performed on the remaining categories. Homogeneity of variances was assessed using Levene's test, with post hoc analysis carried out using Tukey's HSD in the case of equal variances and Tamhane's procedure in the case of unequal variances. Significance was set at 0.05 , two tailed.

\section{Results}

(Table 1).
Table 1. Respondent age profile.

\begin{tabular}{|l|c|c|}
\hline Respondent age profile $(\mathrm{n}=100)$ & N & $\%$ \\
\hline Age Categories & 0 & 0 \\
\hline$<30$ & 29 & 29.0 \\
\hline $30-39$ & 27 & 27.0 \\
\hline $40-49$ & 33 & 33.0 \\
\hline $50-59$ & 11 & 11 \\
\hline $60+$ & & \\
\hline
\end{tabular}

Table 2. Practice characteristics.

Practice Characteristics

Frequency of Cancer Pain Management

\begin{tabular}{|l|c|}
\hline Daily & $9.5 \%(10)$ \\
\hline Weekly & $39.0 \%(41)$ \\
\hline Monthly & $31.4 \%(33)$ \\
\hline Rarely & $20.0 \%(21)$ \\
\hline Level of comfort managing Cancer Pain & \\
\hline Uncomfortable & $0.0 \%(0)$ \\
\hline Comfortable & $22.9 \%(24)$ \\
\hline Very Comfortable & $73.3 \%(77)$ \\
\hline Level of training in Cancer Pain Management & $3.8 \%(4)$ \\
\hline Poor & \\
\hline Adequate & $6.7 \%(7)$ \\
\hline Good & $46.2 \%(48)$ \\
\hline Very Good & $46.2 \%(48)$ \\
\hline Patients receive adequate treatment for pain in my practice setting \\
\hline Strongly Agree & $1.0 \%(1)$ \\
\hline Agree & $7.6 \%(8)$ \\
\hline Disagree & $83.8 \%(88)$ \\
\hline Strongly Disagree & $2.9 \%(3)$ \\
\hline Patients have little control over their pain treatment in my practice setting \\
\hline Strongly Agree & $1.9 \%(2)$ \\
\hline Agree & $11.4 \%(12)$ \\
\hline Disagree & $70.5 \%(74)$ \\
\hline Strongly Disagree & $16.2 \%(17)$ \\
\hline
\end{tabular}

\section{Profile}

A response rate of $76.0 \%(n=105)$ was achieved, comprising $54.3 \%$ males with a median age of 47 years. The median year of medical qualification and specialist qualification was 1987 and 1996 respectively. There was no difference between responders and non-responders in terms of age, gender or year of medical qualification when compared on the Medical Register and no difference between the sample and the population of GPs in the County region in terms of age, sex or year of medical qualification (Table 2).

Almost half of GP's (48.5\%) reported managing cancer pain at least weekly, with $77.1 \%$ reporting they were comfortable or very comfortable managing cancer pain. In terms of their training in cancer pain, $47.2 \%$ rated it as good or very good, with $46 \%$ rating it as adequate and $6.7 \%$ as poor (Table 2). In terms of the treatment and control of cancer pain within the primary care setting, $91.4 \%$ agreed that patients received adequate treatment for pain while $86.7 \%$ disagreed that patients had little control over pain treatment (Tables 3 and 4).

\section{Knowledge}

Knowledge was considered adequate if over $70 \%$ of participants responded correctly. Adequate knowledge scores were obtained for 12 of the 15 knowledge statements. Suboptimal performance (less than $70 \%$ responding correctly) was found in relation to the equivalence of 
opioid products (34\%), the knowledge that chronic pain may not cause changes in vital signs (47.6\%) and the knowledge that opioids do not have a ceiling dose $(56.3 \%)$ (Table 3$)$.

\section{Attitudes}

A high proportion (93.3\%) of respondents agreed that pain management had a high priority for them (Table 4). The problem of cancer pain undertreatment was recognised by $38.8 \%$ and up to a third had concerns in terms of psychological addiction (33.7\%) and physical dependence on (28.2\%) opioids in cancer patients (Table 5).

Table 3. Pain management in primary care setting.

Pain management and treatment

Patients receive adequate treatment for pain in my practice setting

\begin{tabular}{|l|r|}
\hline Strongly Agree & $7.6 \%(8)$ \\
\hline Agree & $83.8 \%(88)$ \\
\hline Disagree & $2.9 \%(3)$ \\
\hline Strongly Disagree & $2.9 \%(3)$ \\
\hline
\end{tabular}

Patients have little control over their pain treatment in my practice setting

\begin{tabular}{|l|l|}
\hline Strongly Agree & $1.9 \%(2)$ \\
\hline Agree
\end{tabular}

\begin{tabular}{|l|l}
\hline Agree & $11.4 \%(12)$
\end{tabular}

\begin{tabular}{l|l}
\hline Disagree & $70.5 \%(74)$
\end{tabular}

\begin{tabular}{|l|l}
\hline Strongly Disagree & $16.2 \%(17)$
\end{tabular}

Table 4. Frequency of correct responses for knowledge questions.

Knowledge statements

Morphine Facts

Morphine is the standard opioid to treat cancer pain

\section{Behaviour}

In terms of reported behaviour, the majority of respondents (77.2\%) reported 'usually' or 'always' undertaking pain assessments, with the majority (93\%) reporting 'never' or only 'occasionally' using a formal pain assessment tool. Most respondents reported 'always' or 'usually' prescribing immediate release (IR) products (69.5\%), strong opioids (63.8\%), paracetamol (57.7\%) and adjuvant medications (55.3\%) while weak opioids were prescribed less frequently. The majority of respondents reported encountering difficulties, side effects and addiction only occasionally (Table 6).

\section{Overall knowledge, attitude, and behaviour scores}

Overall category scores were high with 83 out of 100 achieved in knowledge and 74 out of 100 for attitudes. Overall behaviour score was lower at 64 out of 100 (Table 7).

When compared to demographic and practice characteristics, category scores in knowledge and attitudes were significantly associated with the reported level of comfort in managing cancer pain. Those who rated themselves as comfortable had higher knowledge scores than those who rated themselves as uncomfortable $(\mathrm{F}(2-102)=3.55 ; \mathrm{p}=0.03)$ as well as having higher attitudinal scores $(\mathrm{F}(2-102)=7.70 ; 0=0.001)$. The reported level of training received in cancer pain management was

All malignant pain responds to morphine

Pain due to bony metastases is best relieved by a combination of an opioids and a NSAID

Factual Basis for Assessment

Paitnet with severe chronic malignant pain will have observable changes in vital signs

A patient who is able to sleep cannot be experiencing severe pain

Unrelieved pain results in symptoms such as anxiety, depression and insomnia

Patient Role in Assessment

Severity of pain is best assessed by a doctor or nurse

The patient should have input about dosing intervals for pain medication

The patient is the best judge of whether their pain is controlled

Opioid dosing

For chronic malignant pain, opioids should be dosed on an around the clock, not as needed basis

Short acting morphine is the drug of choice when ordering a breakthrough opioid

For opioid responsive pain there is no ceiling dose of morphine

Equivalency

When changing from one opioid to another it is necessary to start with the lowest dose of the new opioid and retitrate to achieve relief $56.3 \%(58)$

Five milligrams of OxyContin orally is equivalent to 10 miligrams of MST

The accumulation of opioid metabolites can cause symptoms of CNS excitation resulting in confusion and myoclonus

Table 5. Frequency of Agreement with Attitudinal Questions ( $\%$ agree/strongly agree).

Responses to attitude statements

Salience of Pain Management

The skilled management of pain is a high priority for me

Most new patients I see have been undermedicated in the past

Adequate management of severe pain is not much of a problem for me

Lack of Fear of Addiction

I would be concerned if a member of my family were treated with morphine

My management of pain is influenced by my fear of physical dependence on opioids

My management of pain has been influenced by my experience with patients with Psychological addiction

Lack of Fear of Regulation

My fear of being investigated influences my prescribing of opioids

Prescribing unrelated to Prognosis

Maximum doses of opioids should only be used when prognosis is $<6$ months

$\%$ agree/strongly agree 
Table 6. Reported frequency of reported behaviours.

\begin{tabular}{|l|l|l|l|l|}
\hline \multicolumn{4}{|c|}{ Behaviour Questions } & \multicolumn{3}{l|}{ Frequency (\%) } \\
\cline { 2 - 6 } & Never & Occasionally & Usually & Always \\
\hline Frequency of difficulties & 2.9 & 83.8 & 13.3 & 0 \\
\hline Frequency of side effects & 1.9 & 91.4 & 6.7 & 0 \\
\hline Frequency of addiction & 35.6 & 57.7 & 6.7 & 0 \\
\hline Frequency of pain assessments & 1.9 & 21 & 61 & 16.2 \\
\hline Frequency of formal assessment tool use & 63.8 & 29.5 & 6.7 & 0 \\
\hline Frequency of prescribing IR products & 1.9 & 27.6 & 53.3 & 17.1 \\
\hline Frequency of adjuvant use & 1 & 43.8 & 52.4 & 2.9 \\
\hline Frequency of prescribing paracetamol & 3.8 & 38.5 & 40.4 & 17.3 \\
\hline Frequency of prescribing weak opioids & 2.9 & 62.5 & 28.8 & 5.8 \\
\hline Frequency of prescribing strong opioids & 4.8 & 31.4 & 56.2 & 7.6 \\
\hline
\end{tabular}

Table 7. Overall scores.

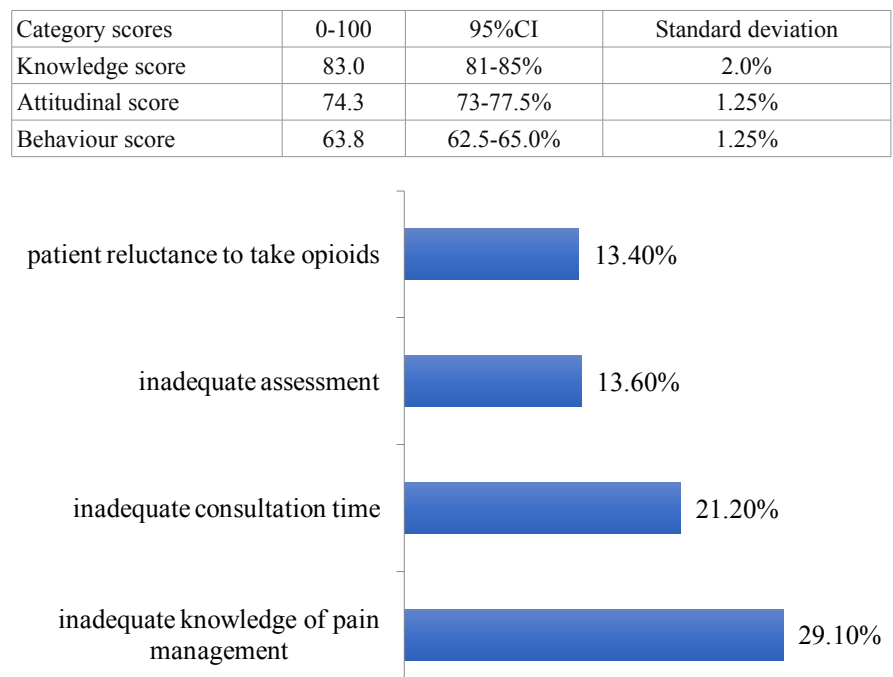

Figure 1. Barriers Most Frequently Ranked Number 1.

also found to be significantly related to attitude score $(t(102)=-1.99$; $\mathrm{p}=0.05$; 95\%CI $-0.27-0.00)$, with those rating their training as either poor or average $(\bar{x}=2.91 ; \mathrm{SD}=0.40)$ having a lower mean attitude score than those rating their training as either good or very good $(x=3.05 ; \mathrm{SD}=0.49)$. Category behaviour scores were also found to be associated with gender $(\mathrm{t}(143)=4.88 ; \mathrm{p}=0.00)$ with female gender being associated with higher behavior scores (female $=2.81 ; \mathrm{SD}=0.38$; males $=2.53 ; \mathrm{SD}=0.30$ ).

\section{Barriers}

Out of the list of potential barriers to adequate analgesia, almost one-third (29.1\%) ranked inadequate knowledge of pain management as the first out of ten potential barriers. The second barrier to be most frequently ranked number one was inadequate consultation time with $21.2 \%$ of respondents ranking this as the top barrier. Inadequate assessment was ranked first by $13.6 \%$, while patient reluctance to take opioids was ranked number one by $13.4 \%$ (Figure 1).

\section{Discussion}

The assessment of physician barriers to cancer pain treatment represents a key component in terms of ensuring that cancer pain is effectively managed. Within the Irish context, GPs are the primary providers of cancer pain management. This study is therefore important as it provides an assessment from a representative sample of
GPs from one region in Ireland [12,13]. Overall, knowledge, attitudes, and behaviour were appropriate in term of cancer pain management. However, a number of discrepancies are apparent which require more detailed consideration.

The GPs in the study were experienced practitioners. Over half were frequently involved in cancer pain management (weekly or more often) with over three quarters (77\%) comfortable or very comfortable with their management. Almost nine out of ten believed patients both received adequate treatment for pain and had control over their pain treatment. However, only $39 \%$ recognised that their patients had been undertreated in the past. This is in contrast to International and Irish evidence which show that cancer pain is undertreated [14,15]. Parallel research of patients in the study area also found that over three quarters of palliative cancer patients reported uncontrolled pain. One possible explanation for these findings is that GPs may not possess sufficient skills in cancer pain management and as such may not recognise that their treatment may be suboptimal. Perceptions of training were mixed, with over half rating it as adequate and almost half rating it as good. Those rating their training as poor or adequate also had significantly lower attitude scores. This, combined with the fact that GP training in Ireland does not include mandatory clinical experience in palliative care suggests that GPs may be unaware that they are underestimating cancer pain [16].

Knowledge was generally adequate $(>70 \%$ correct) with suboptimal performance in relation to the equivalence of opioid products, the impact of pain on changes in vital signs, and knowledge of the lack of a ceiling dose for opioids. These deficits have been desmontrated in physician populations internationally in levels similar to those found in this population. These deficits have the potential to contribute to inadequate pain management through ineffective prescribing or prescribing in doses too low to achieve analgesia. In addition, almost a third ranked inadequate knowledge as the top barrier to adequate analgesia. Previous explorations have identified significant training needs in relation to cancer pain management among Irish GPs, and internationally, inadequate training is consistently reported by physicians as a significant barrier to the adequate management of cancer pain, regardless of speciality [3,7,15,17-19].

As with knowledge, overall attitudes were appropriate. However, responses to some of the statements indicate that some GPs may possess inappropriate attitudes and beliefs, including exaggerated levels of concern regarding psychological addiction and physical dependence, issues that are known not to be problematic in this patient population [9]. Generally, reported behaviour was condusive to adequate pain management though again, deficits were demonstrated. While over three quarters reported regularly undertaking pain asessments, only a small number reported using a formal pain assessment tool. Given the consistently demonstrated tendency for physicians to under report patient pain, this could contribute to inadequate pain management through underassessment of pain severity [20].

This study is limited in that it was a self-reported survey of knowledge, attitudes and behaviours. Results therefore may not represent actual knowledge or practice and actual levels may be lower than those described. While the GP respondents were representative of the sample from which they were drawn regionally, national representativeness cannot be determined. The region in which this study took place is one with a high level of palliative care support, and given the consultative model of palliative care in Ireland, practice may be more appropriate in well supported areas. 


\section{Conclusions}

The GPs involved in this study displayed much of the knowledge, attitudes and behaviours thought to be conducive to good cancer pain management. Despite this, the evidence from a parallel study suggests that patients remain in pain. This study demonstrates that even small deficits can translate into uncontrolled cancer pain, highlighting the need for specialised training and the use of formal tools to support best practice among GPs.

\section{Disclosures and acknowledgements}

The authors have no conflict of interest of funding disclosures.

\section{References}

1. Deandrea S, Montanari M, Moja L, Apolone G (2008) Prevalence of undertreatment in cancer pain. A review of published literature. Ann Oncol 19: 1985-1991. [Crossref]

2. Ferrell BR, Griffith H (1994) Cost issues related to pain management: report from the cancer pain panel of the agency for health care policy and research. J Pain Symptom Manage 9: 221-234.

3. MacDonald N, Ayoub J, Farley J, Foucault C, Lesage P, et al. (2002) A Quebec survey of issues in cancer pain management. J Pain Symptom Manage 23: 39-47. [Crossref]

4. Vallerand AH, Templin T, Hasenau SM, Riley-Doucet C (2007) Factors that affect functional status in patients with cancer-related pain. Pain 132: 82-90. [Crossref]

5. Devi BC, Tang TS, Corbex M(2006) What doctors know about cancer pain management: an exploratory study in Sarawak, Malaysia. J Pain Palliat Care Pharmacother 20: 15 22. [Crossref]

6. Zech DF, Grond S, Lynch J, Hertel D, Lehmann KA (1995) Validation of World Health Organization Guidelines for cancer pain relief: a 10-year prospective study. Pain 63: 65-76. [Crossref]
7. Von Roenn JH, Cleeland CS, Gonin R, Hatfield AK, Pandya KJ (1993) Physician attitudes and practice in cancer pain management. A survey from the Eastern Cooperative Oncology Group. Ann Intern Med 119: 121-126. [Crossref]

8. Weissman DE, Haddox JD (1989) Opioid pseudoaddiction--an iatrogenic syndrome. Pain 36: 363-366. [Crossref]

9. Colleau S (1998) Physical dependence and addiction: definitions, clinical relevance and misconception. WHO Pain and Palliative Care Communications Programme 11(3).

10. Levin M, Berry J, Leiter J (1998) Management of pain in terminally ill patients: physician reports of knowledge, attitudes and behaviour. J Pain Symptom Manage15: 27-40. [Crossref]

11. National Medicines Information Centre (2005) Pharmacological Management of pain in primary care. Opioids 11: 1-6.

12. Doran G (2012) ICGP Physician Demographic Profile as of September 2011.

13. Irish Medical Council (2012) Register of Medical Practitioners. www.medicalcouncil.ie

14. Higginson IJ, Hearn J (1997) A multicenter evaluation of cancer pain control by palliative care teams. J Pain Symptom Manage 14: 29-35. [Crossref]

15. McDarby G (2015) Barriers to the adequate management of cancer pain in patients with advanced cancer. MFPHMI, Royal College of Physicians, Ireland.

16. O’Dowd T, O’Kelly M, O'Kelly F (2006) Structure of General Practice in Ireland 19822005, Irish College of General Practitioners.

17. Walsh D, Regan J (2001) Terminal care in the home--the general practice perspective. Ir Med J 94: 9-11. [Crossref]

18. Dowling S, Leary A, Broomfield (2005) Education in palliative care: a questionnaire survey of Irish general practitioner trainees. Education for Primary Care 16: 42-50.

19. Dowling S, Leary A, Broomfield (2005) Palliative care education: a Delphi survey of Irish general practitioners. Education for Primary Care 16: 458-466.

20. Marquié L, Raufaste E, Lauque D, Mariné C, Ecoiffier M, et al. (2003) Pain rating by patients and physicians: evidence of systematic pain miscalibration. Pain 102: 289-296. [Crossref]

Copyright: (C2017 McDarby G. This is an open-access article distributed under the terms of the Creative Commons Attribution License, which permits unrestricted use, distribution, and reproduction in any medium, provided the original author and source are credited. 